\title{
Spatiotemporal trends of precipitation on the Loess Plateau of China
}

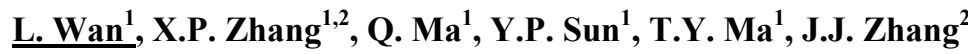 \\ 1. State Key Laboratory of Soil Erosion and Dry Land Farming on the Loess Plateau, Northwest A\& F \\ University, Yangling, Shaanxi 712100, China; 2. Institute of Soil and Water Conservation, CAS \& MWR, \\ Yangling, Shaanxi 712100, China \\ Email:wanlong101@yahoo.com.cn; zhangxp@ms.iswc.ac.cn
}

\begin{abstract}
Spatiotemporal trend of precipitation potentially influences vegetation restoration and soil erosion on the Loess Plateau. Daily data at 100 meteorological stations in and around the area from 1957 to 2009 were used to analyze the spatiotemporal trends of precipitation and the return periods of the different types of precipitation classified in the study. Nonparametric methods (Mann-Kendall and Sen's slope estimation) were employed for temporal analysis and Kriging interpolation method, for spatial analysis.

The annual precipitation was detected to have a slight decreasing trend at 0.1 significance level on the Loess Plateau and no change point existed. The decreasing rate changed from a negative value up to $-3 \sim-7 \mathrm{mma}^{-1}$ in southeast to a positive value up to $1 \sim 2 \mathrm{mma}^{-1}$ in northwest. The average annual decreasing rate was found to be $-1.15 \mathrm{~mm} \mathrm{a}^{-1}$ accounting for $0.26 \%$ of the average annual precipitation. The area with decreasing trend accounted to $86 \%$ of the total area of the Loess Plateau.
\end{abstract}

Only except for the winter, the regional precipitation in other seven time series, i.e., spring, summer, autumn, wet season, dry season, EFP (early flood period), and LFP (late flood period), presented insignificantly decreasing trends. The areas for the seven time series were up to $70 \%, 72 \%, 83 \%, 84 \%, 90 \%, 56 \%$ and $89 \%$ of the total area, respectively.

The shifts of the 150, 250, and $350 \mathrm{~mm}$ isohyets were not evident between the decades. The weighted average centers of the 450 and $550 \mathrm{~mm}$ isohyets moved $134 \mathrm{~km}$ eastwards and $213 \mathrm{~km}$ westwards from $1960 \mathrm{~s}$ to $1990 \mathrm{~s}$. However, the two centers retreated $12.1 \mathrm{~km}$ westwards and $54.8 \mathrm{~km}$ northwards from $1990 \mathrm{~s}$ to 2000 s.

The frequencies of the precipitation types defined with Moderate, Heavy, Rainstorm, and Heavy Rainstorm were detected to have decreasing trends from $1960 \mathrm{~s}-2000 \mathrm{~s}$, based on the decadal analysis. The return periods of the four types of precipitation changed from $0.13,0.39,1.82,19.80 \mathrm{a}$ in 1960 s to $0.15,0.39,2.34$, and $26.88 \mathrm{a}$ in $2000 \mathrm{~s}$.

Results indicates a small drier precipitation change of no significance given by Mann-Kendall test, the shifted southward precipitation isohyets, a slightly delayed rainy season, and the prolonged return period especially in rainstorm and heavy rainstorm types in the last 53 years. Global climate change seemly did not influence the Loess Plateau of China greatly, but the variations of precipitation apparently took place both in spatial and temporal dimensions on the Loess Plateau from 1960s to 2000s.

Keywords: Spatial distribution change, temporal trend, Return period, Precipitation, Loess Plateau. 


\section{INTRODUCTION}

Global warming over the last 100 years and the consequent increase in the moisture-holding capacity of the atmosphere (IPCC, 2007) imply that a more intense hydrological cycle would occur (Held and Soden, 2006). Because of the change, the alteration of spatiotemporal characteristics of precipitation and the changes of associated heavy precipitation frequencies are critical especially in arid and semiarid regions.

The change of precipitation is not uniform from place to place in the world. Precipitation gauge data indicate that global land precipitation (excluding Antarctica) was increased by $0.89 \mathrm{~mm}$ per decade over the twentieth century (New et al., 2001). The annual precipitation in Northern Norway was increased by $15 \%$ and in Germany, less than 10\% during the last century (Førland and Hanssen-Bauer, 2000; Hänsel et al, 2009). Although an increasing trend of the annual precipitation from 1950 to 2006 was found in USA (Easterling et al., 2007), a decreasing trend was observed in Southern Peru and Southern Chile (Haylock et al., 2005). In Northeast Brazil and Northern Amazonia, a positive trend of no significance occurred in rainy season (Marengo et al.,1998), while in China, a significant increasing trend of annual precipitation from June to August was detected which potentially aggravate flood hazards in the Yangtze River basin (Jiang et al., 2008).

On the Loess Plateau the long agricultural history, sparse vegetation, and high intensity rainstorms have caused the severest soil erosion in the world (Tang,1990). To reduce soil erosion, various soil conservation measures have been implemented on the Loess Plateau since 1950s. Furthermore, the "Grain for Green" project has been implemented to reconstruct its ecosystem since 1999. The spatiotemporal trend of precipitation potentially determines the physical environment of vegetation restoration on the Loess Plateau. Also from the long-term experiments and practices of soil and water conservation, both volume and intensity of precipitation are found to be the critical factors controlling soil erosion processes (Tang, 1990).

A decreasing trend of annual precipitation after 1950s on the Loess Plateau was detected (Xin et al., 2009). $\mathrm{Xu}$ et al. (2007) also reported that precipitation in spring and autumn was found to decrease based on the data from a great percentage of stations. However, the spatiotemporal trend of precipitation on the Loess Plateau has not been stated systematically. In addition, how precipitation types change is not fully understood, especially for extreme precipitation events. Understanding precipitation changing patterns is essential for water resources management and soil erosion controlling on the Loess Plateau. Therefore, the specific objectives of the study were to: (1) detect the annual precipitation trend and the isohyet's change in the study area, (2) identify the spatiotemporal variability of the seasonal trend, and (3) find the spatiotemporal change in recurrence period of extreme precipitation events.

\section{STUDY AREA}

The location of the Loess Plateau in China is showed in Fig.1. The Loess Plateau of $620,000 \mathrm{~km}^{2}$ is located in the middle reaches of the Yellow River $\left(750,000 \mathrm{~km}^{2}\right)$, with its elevation varying from 800 to 2000 $\mathrm{m}$. The northwest part of the Loess Plateau is the sandy lands. Gullies and hills dominate the middle and southeast part. The desert-steppe, typical-steppe, forest-steppe, and forest zones distribute from northwest to southeast. The wind deposited loess soils cover nearly all the plateau and are approximately 50 to $200 \mathrm{~m}$ deep. Average annual precipitation on the Loess Plateau

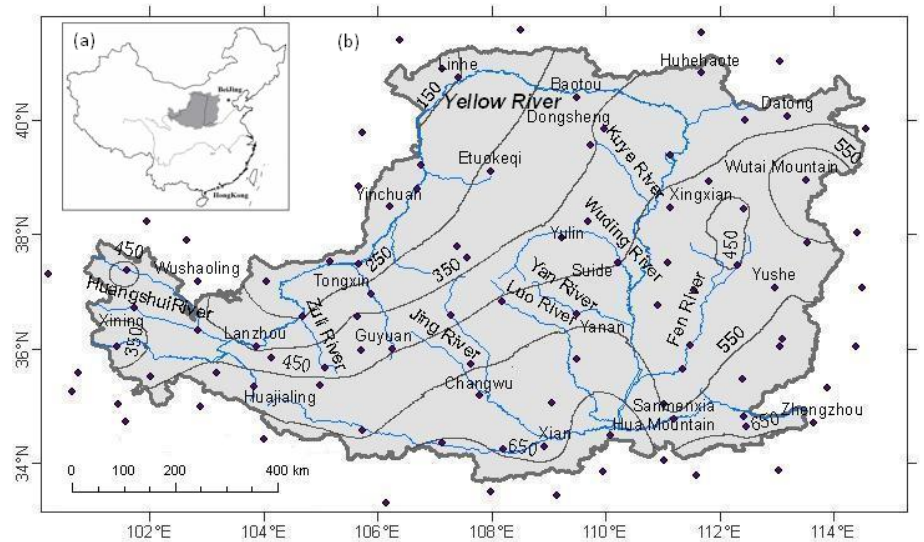

Figure. 1. (a) shows the location of the Loess Plateau (gray shading) in the middle reaches of the Yellow River basin. (b) shows the distribution of the meteorological stations on and around the Loess Plateau and the mean annual isohyets of 550, 450, 350, and $250 \mathrm{~mm}$. ranges from more than $800 \mathrm{~mm}$ in the southeast to less than $150 \mathrm{~mm}$ in the northwest. More than $78 \%$ of annual precipitation on the Loess Plateau occurs from May to October and in the northwest the percentage is greater $(85 \% \sim 92 \%)$. Intensive rainstorms result in severe soil erosion in the area with annual precipitation from 350 to $450 \mathrm{~mm}$ (Fig.1). The amount of annual soil erosion is estimated to be over 2000 3000 million tons (Tang, 1990). 


\section{DATA AND METHODS}

\subsection{Data Description}

The daily precipitation data at 100 meteorological stations from 1957 to 2009 on and around the Loess Plateau were used for our analyses (Fig. 1(b)). Totally, 89 stations were selected to examine the seasonal trends and return periods. All the data were obtained from the China Meteorological Administration. The dataset was divided into 8 time series to examine their precipitation trends:

- $\quad$ spring : March to May

- summer: June to August

- autumn: September to November

- winter: December to the following January

Changes in precipitation frequency and return period, especially frequency of the extreme precipitation events (greater than $50 \mathrm{~mm}$ ), can strongly influence soil erosion processes on the Loess Plateau (Tang, 1990). Therefore, four precipitation types were classified to investigate the spatiotemporal variations of their frequencies and return periods, as showed in Table 1.
- wet season: May to October

- dry season: November to next April

- EFP(early flood period): May to July

- LFP(late flood period): August to October

Table 1. Classification of precipitation types on the Loess Plateau.

\begin{tabular}{ll}
\hline Classification & Level (mm/day) \\
\hline Moderate $(\mathrm{M})$ & $12 \sim 24.9$ \\
Heavy $(\mathrm{H})$ & $25 \sim 49.9$ \\
Rainstorm (R) & $50 \sim 99.9$ \\
Heavy rainstorm (HR) & $100 \sim 200$ \\
\hline
\end{tabular}

\subsection{Methods}

The surfaces of annual precipitation for each year from 1957 to 2009 were created by using the ordinary Kriging interpolation method based on the annual precipitation of each station and then summed up to give the whole area by using area weighted average method. The spherical model with a grid resolution of $500 \times 500 \mathrm{~m}$ was used and the fitted parametric isotropic semivariogram for each map was obtained by using an approximate weighted least squares criterion. Nonparametric Mann-Kendall method proposed by Mann (1945) and improved by Kendall (1975) was widely used to test trends in hydrological and climatological time series. This method has been recommended by the World Meteorological Organization (1988) as a standard procedure for detecting trends in hydrological data. The time series was pre-whitened to eliminate the effect of serial correlation before applying the Mann-Kendall teat. Sen's estimator was used to estimate the changing rate in the data records (Sen, 1968). Return Period or frequency analysis is used to estimate the probability of the occurrence of a given precipitation event. The regional frequencies of the four types of precipitation were calculated by using arithmetical average method.

\section{RESULTS AND DISCUSSION}

\subsection{Trends of Annual Precipitation}

Average annual precipitation on the Loess Plateau was found to be $434.4 \mathrm{~mm}$. An insignificant decreasing trend of the annual precipitation from 1957-2009 was detected $(0.1<\mathrm{p}<0.05)$, with an average decreasing rate

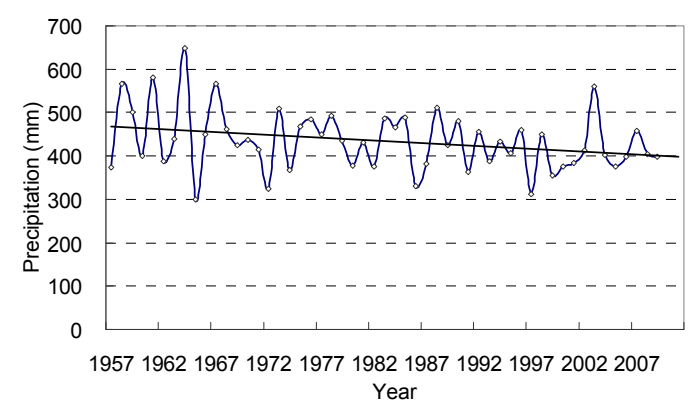

(a) Trend of the annual precipitation on the Loess Plateau

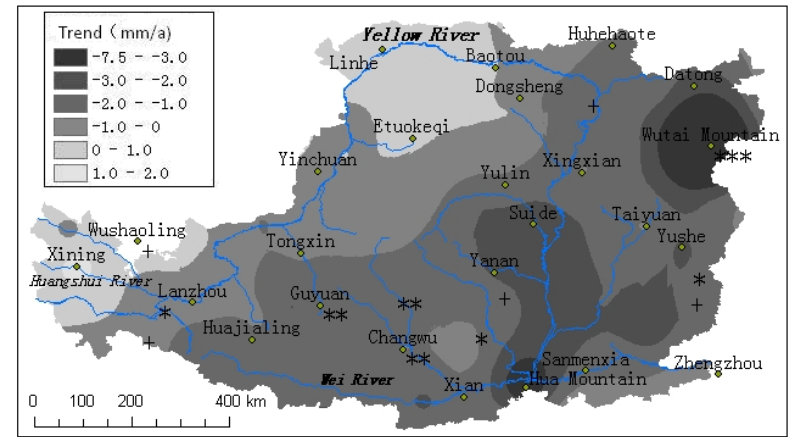

(b) Trend surface of annual precipitation

Figure. 2. Annual precipitation trend (a) and trend surface of annual precipitation (b) on the Loess Plateau. (the symbols “+”, “*”, "**”, and "***" indicate the statistical significance level at $0.1,0.05,0.01$, and 0.001 by Mann-Kendall test, respectively.) 
of $-1.15 \mathrm{mma}^{-1}$, which account for about $0.26 \%$ of the average annual precipitation. Fig. 2(a) shows a greater variation of precipitation in the 1960s but much weaker variation in other decades.

From the spatial distribution of the annual precipitation trends on the Loess Plateau, $86 \%$ of the total area of the Loess Plateau exhibited a decreasing trend, whereas only 14\%, an increasing trend (Fig. 2(b)). The magnitudes of the trends ranged from $-3 \sim-7 \mathrm{mma}^{-1}$ in the southeast to $1-2 \mathrm{mma}^{-1}$ in the northwest. The area with increasing trend concentrated in the northern and western parts. The region with the significant decreasing trend $(p<0.05)$ included the lower reaches of Wuding River, Yan River basin, and Fen River basin. Its center was in the area surrounded by Wutai, Hua and Liupan Mountains (Fig. 2(b)).

\subsection{Trend Tests for Seasonal Time Series}

Remarkable differences existed in the trend directions and the change rates between seasons. Precipitation in the winter series had an insignificant increasing trend over the whole period, while in all other series, insignificant decreasing trends (Table 2). Table 2 shows that the average changing rate of the rainy season represented by summer, wet season, FEP and LFP in the region, is 4.5 times of that in other series. Fig. 3 shows that $85 \%$ of the total area in the winter presented increasing trend. And the areas for the decreasing trends of precipitation in other 7 time series varies form $56 \%$ to $90 \%$. The decreasing trend (Table 2) and its area (Fig. 3) in the wet season imply a delayed flood period and a drier weather condition in the period.

Table 2. Average change rates of seasonal areal precipitation $(\mathrm{mm} / \mathrm{a})$ estimated by Sen's estimator.

\begin{tabular}{|c|c|c|c|c|c|c|c|c|}
\hline & spring & Summer & autumn & winter & wet season & dry season & EFP & LFP \\
\hline Sen's slope & -0.09 & -0.57 & -0.19 & 0.065 & -0.80 & -0.29 & -0.45 & -0.47 \\
\hline
\end{tabular}

The increasing trends in these seasons mostly distributed in the northwestern part of the Loess Plateau. The strong decreasing trends mostly occurred in the downstream of Wuding River, Yan River, the downstream of Wei River, the Liupan Mountains, Wutai Mountains and Hua Mountains (Fig.3).

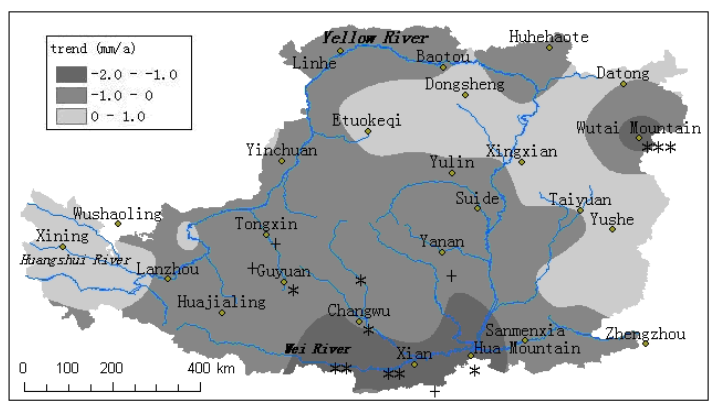

(a) For spring ( $70 \%$ of total area with a decreasing trend)

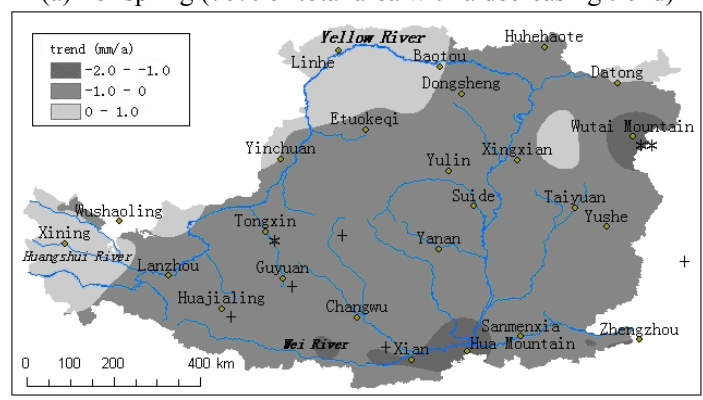

(c) For autumn ( $83 \%$ of total area with a decreasing trend)

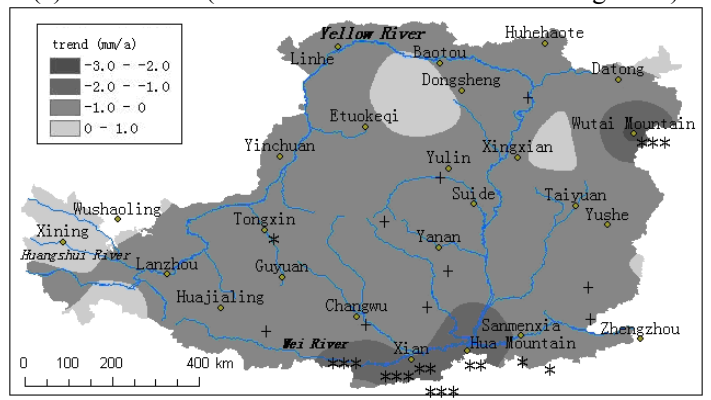

(e) For dry season (90\% of total area with a decreasing trend)

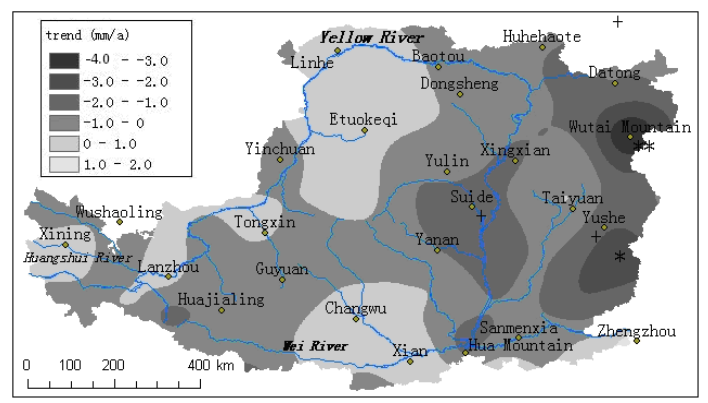

(b) For summer ( $72 \%$ of total area with a decreasing trend)

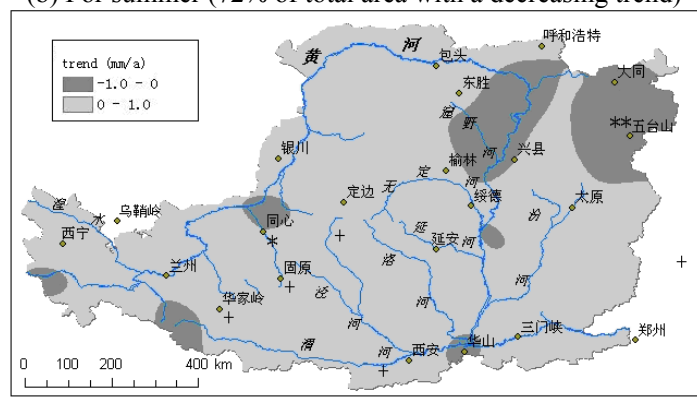

(d) For winter ( $85 \%$ og total area with an increaing trend)

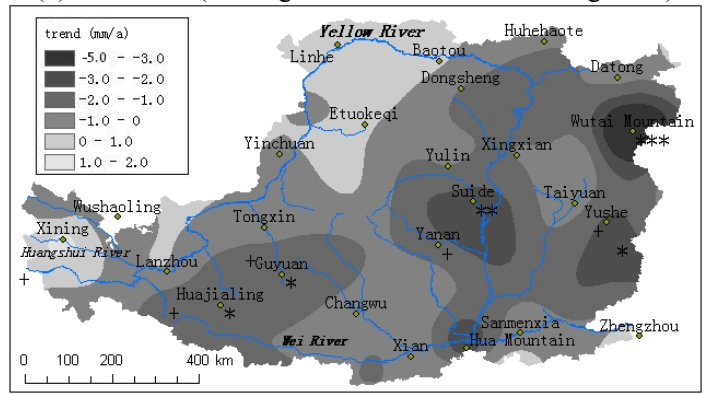

(f) For wet season ( $84 \%$ of total area with a decreasing trend) 


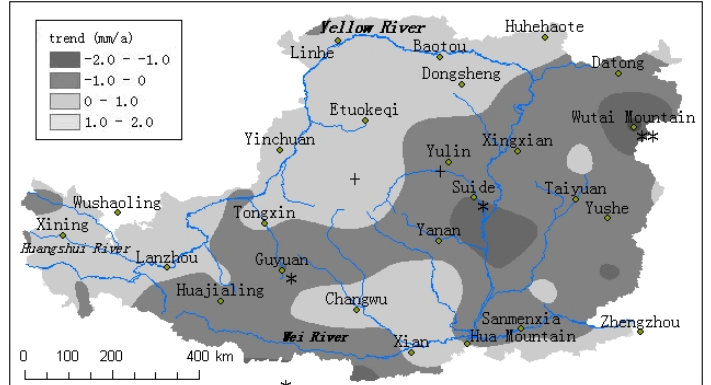

(g) For EFP (56\% of total area with a decreasing trend)

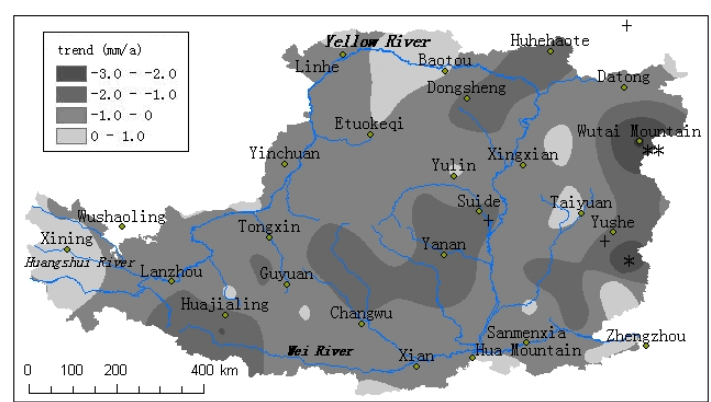

(h) For LFP ( $89 \%$ of total area with a decreasing trend)

Figure 3. Spatial distribution of the seasonal trends for the 8 series.

\subsection{Trends of Isohyets}

The 550, 450, and $250 \mathrm{~mm}$ isohyets are three important reference lines to identify the vegetation zones from forest to forest-steppe, typical steppe, and desert steppe on the Loess Plateau. The area between the mean annual isohyets of 350 and $450 \mathrm{~mm}$ also strongly suffers from soil erosion by both wind and water and hence, is considered as a major source of coarse sand on the downstream bed of the Yellow River.

Fig. 4 illustrated that the shifts of the 150, 250, and $350 \mathrm{~mm}$ isohyets were not evident. The shift directions from decade to decade were not consistent and most of the shift distances were less than $30 \mathrm{~km}$. However, the shifts of the 450 and $550 \mathrm{~mm}$ isohyets were much evident. From 1960s to 1990s, the centroid of $450 \mathrm{~mm}$ isohyet moved about $133.8 \mathrm{~km}$ eastward and the $550 \mathrm{~mm}$ isohyet, $81 \mathrm{~km}$ eastward and $212.7 \mathrm{~km}$ southward. From 1990s to 2000s, conversely, the centroid of $450 \mathrm{~mm}$ isohyet retreated about $12.1 \mathrm{~km}$ westward and the $550 \mathrm{~mm}$ isohyet, about $14.8 \mathrm{~km}$ westward and $54.8 \mathrm{~km}$ northward. The southeast shifts of the 450 and 550 $\mathrm{mm}$ isohyets may indicate a southeast shift of the forest-steppe and typical steppe zones.

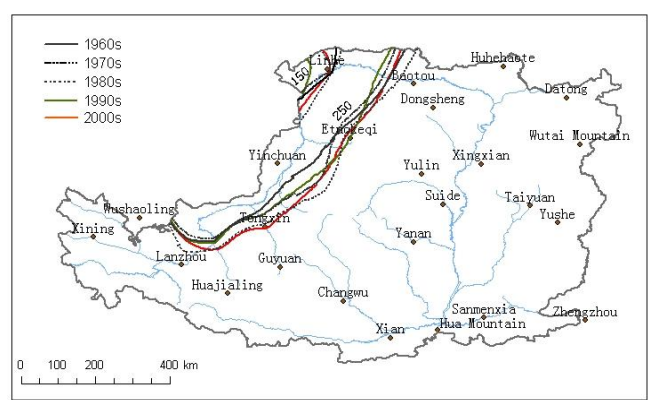

(a) The 150 and $250 \mathrm{~mm}$ isohyets in ten years scale

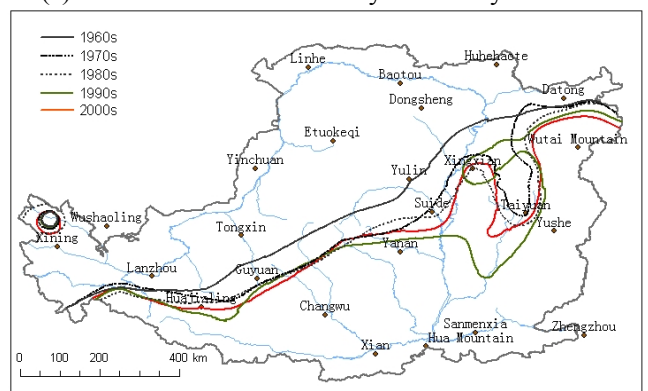

(c) The $450 \mathrm{~mm}$ isohyet in ten years scale

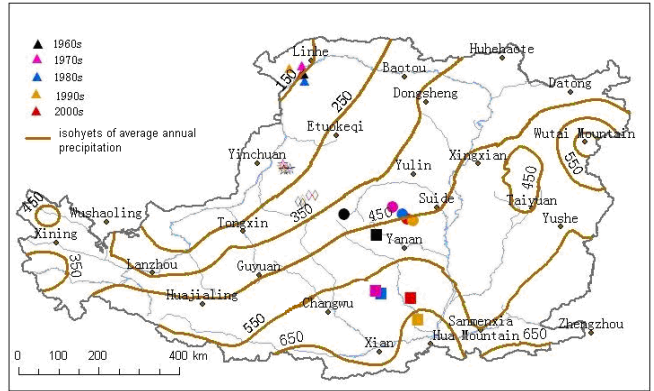

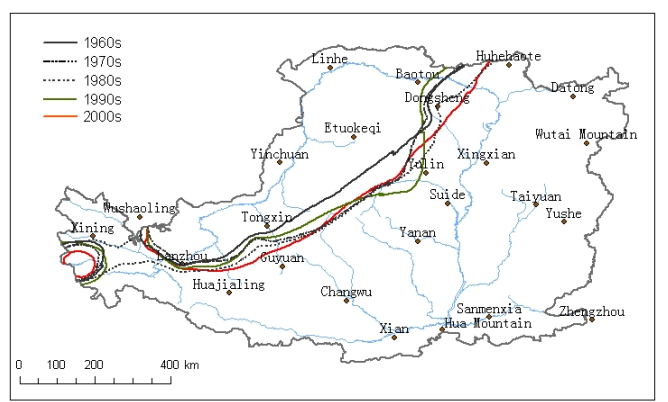

(b) The $350 \mathrm{~mm}$ isohyet in ten years scale

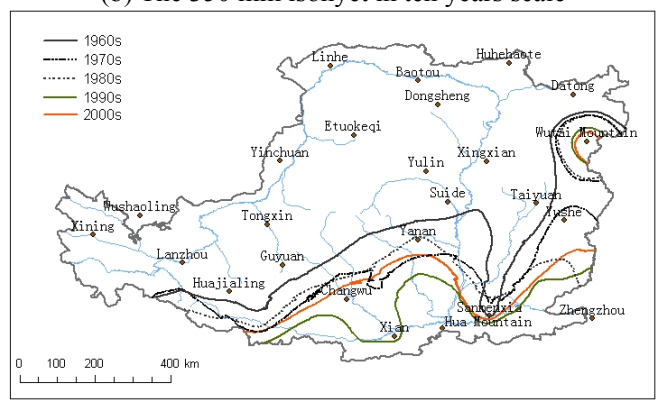

(d) The $550 \mathrm{~mm}$ isohyet in ten years scale

(e) (The left plot)The location of the centroids of the isohyets. The symbol of triangle, star, diamond, round point and square express the centroids of $150,250,350,450$ and $550 \mathrm{~mm}$ isohyets, respectively.

Figure. 4. The isohyets and their centroids for each decade from 1960s to 2000s on the Loess Plateau. 


\subsection{Changes of Return Period}

Fig. 5 shows a southeast to northwest decreasing trend of the average annual days for the M, H, R, and HR types of precipitation on the Loess Plateau. The frequencies of the four types of precipitation in the southeast were up to $127.30,63.02,16.50$, and $2.44 \mathrm{~d}$ per decade and in the northwest, up to17.90, 0.05, 0.01, and $0 \mathrm{~d}$ per decade, respectively. The regional frequencies per decade for the four types were 72.6, 25.8, 4.9, and 0.4 $\mathrm{d}$, respectively (Table 3 ). This means that the regional return periods per decade for the four types is 0.14 , $0.39,2.02$, and 24.51 a, respectively.

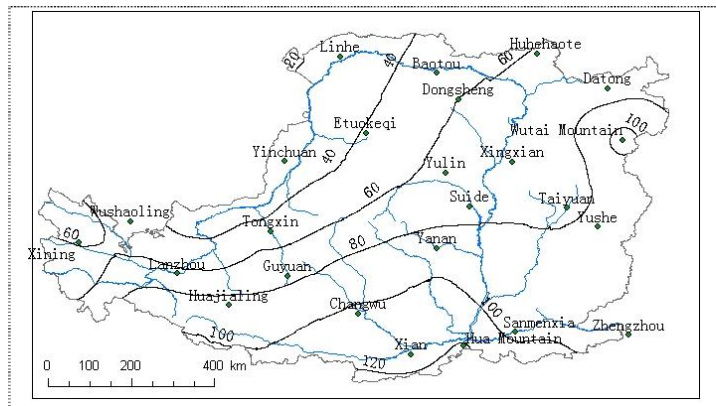

(a) Frequency distribution for the $M$ type

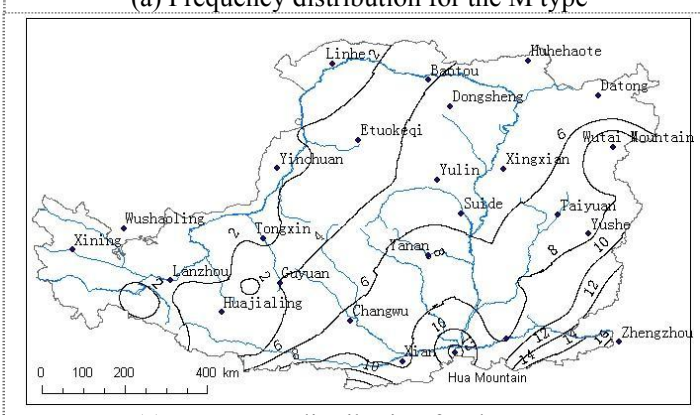

(c) Frequency distribution for the R type

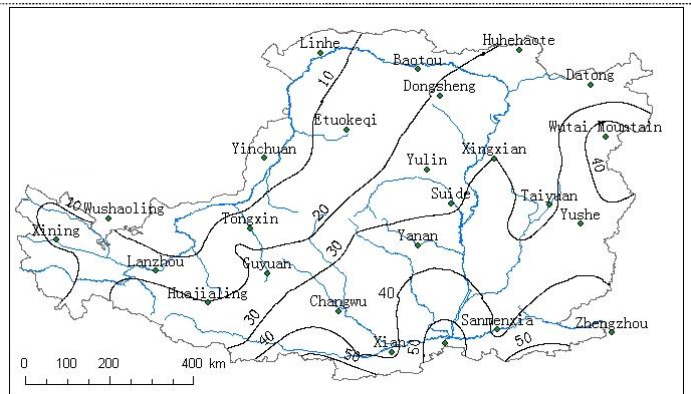

(b) Frequency distribution for the $\mathrm{H}$ type

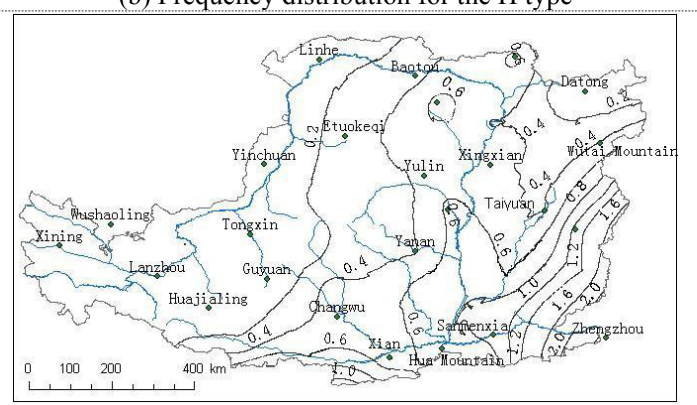

(d) Frequency distribution for the HR type

Fig. 5. Isohyets of average annual rainy days (d/decade) for each type of precipitation on the Loess Plateau.

Table 3 also gives the frequencies with a decreasing trend for the four types of precipitation. The regional frequencies for the four types changed from 79.54, 25.97, 5.49, and $0.51 \mathrm{~d}$ in 1960 s to $68.91,25.48,4.28$, and $0.37 \mathrm{~d}$ in $2000 \mathrm{~s}$. The average decreasing rates in frequency for the four precipitation types were $16.0 \% 3.4 \%$, $35.5 \%$, and $42.8 \%$, respectively. The return periods for the four types changed from $0.13,0.39,1.82$, and $19.80 \mathrm{a}$ in $1960 \mathrm{~s}$ to $0.15,0.39,2.34$, and $26.88 \mathrm{a}$ in $2000 \mathrm{~s}$. This means that the regional recurrence interval was prolonged in recent decades.

Table 3. Decadal variability of the regional frequencies (d/decade) and the regional return periods (a) for each precipitation type in each decade on the Loess Plateau.

\begin{tabular}{|c|c|c|c|c|c|c|c|c|c|c|c|c|c|}
\hline \multirow{2}{*}{$\begin{array}{l}\text { Precipitation } \\
\text { type }\end{array}$} & \multicolumn{2}{|c|}{$1960 \mathrm{~s}$} & \multicolumn{2}{|c|}{$1970 \mathrm{~s}$} & \multicolumn{2}{|c|}{$1980 \mathrm{~s}$} & \multicolumn{2}{|c|}{$1990 \mathrm{~s}$} & \multicolumn{2}{|c|}{$2000 \mathrm{~s}$} & \multicolumn{2}{|c|}{ 1957-2009 } & \multirow{2}{*}{$\begin{array}{l}\text { Decreasing } \\
\text { ratio for } \mathrm{Fq}\end{array}$} \\
\hline & $\mathrm{Fq}$ & $\mathrm{RP}$ & $\mathrm{Fq}$ & $\mathrm{RP}$ & $\mathrm{Fq}$ & $\mathrm{RP}$ & $\mathrm{Fq}$ & $\mathrm{RP}$ & $\mathrm{Fq}$ & $\mathrm{RP}$ & $\mathrm{Fq}$ & $\mathrm{RP}$ & \\
\hline M & 79.54 & 0.13 & 71.67 & 0.14 & 72.50 & 0.14 & 69.66 & 0.14 & 68.91 & 0.15 & 72.61 & 0.14 & $-16.0 \%$ \\
\hline $\mathrm{H}$ & 25.97 & 0.39 & 24.74 & 0.40 & 25.34 & 0.39 & 23.96 & 0.42 & 25.48 & 0.39 & 25.80 & 0.39 & $-3.4 \%$ \\
\hline $\mathrm{R}$ & 5.49 & 1.82 & 5.53 & 1.81 & 4.34 & 2.31 & 4.44 & 2.25 & 4.28 & 2.34 & 4.94 & 2.02 & $-35.5 \%$ \\
\hline HR & 0.51 & 19.80 & 0.47 & 21.28 & 0.37 & 27.17 & 0.39 & 25.84 & 0.37 & 26.88 & 0.41 & 24.51 & $-42.8 \%$ \\
\hline
\end{tabular}

Note: Fq and RP mean the frequency and return period of precipitation events, respectively.

The high quality daily data of precipitation at 20 stations evenly distributed in the study area were used for further comparison of frequency variation for the $\mathrm{H}$ and HR types of precipitation (Fig. 6). The frequencies for the two types presented a significant decreasing trend from 1960 s to 2000s. In the north of the Loess Plateaus, the R type of precipitation occurred $7 \mathrm{~d}$ at Huhehaote station and $8 \mathrm{~d}$ at Dongsheng station in 1960s, but decreased to only 4 and $1 \mathrm{~d}$ in 2000s, respectively. The HR type of precipitation event occurred 1 3 d at the stations in 1960s and however, did not occur in 2000s at all. In the central region of the Loess Plateau, the $\mathrm{R}$ type of precipitation occurred $7 \mathrm{~d}$ at Guyuan station, $10 \mathrm{~d}$ at Xixian station, and 11d at Yanan station in 1960 s, but only 2, 5, and 7d in 2000s, respectively. However, an increasing trend for the HR type was found at Xi'an and Changwu stations located in the south part of the Loess Plateau. The HR type of precipitation did not occur from 1960s to 1980 s, but it occurred 1d/decade from 1990s to 2000s. 


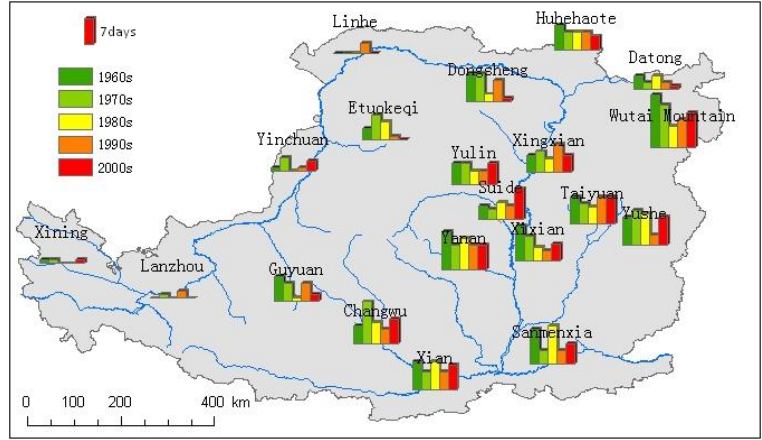

(a) For R event

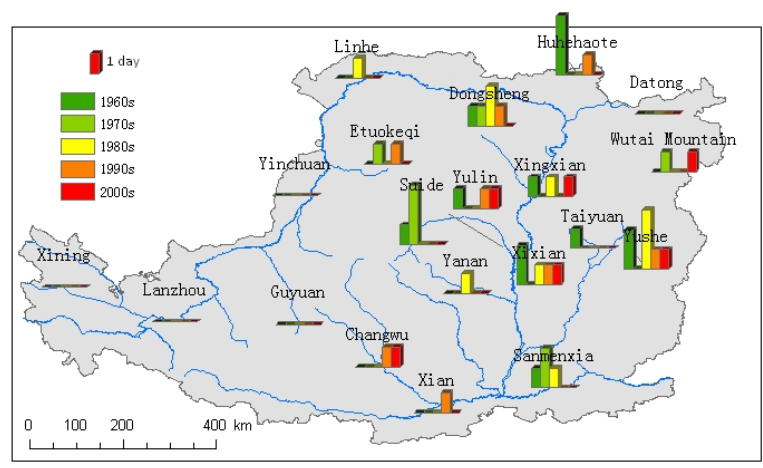

(b) For HR event

Figure. 6. Decadal variability of frequency for the R and HR types of precipitation at 20 stations on the Loess Plateau.

\section{CONCLUSIONS}

This study examined the spatiotemporal trends of precipitation on the Loess Plateau from 1957 to 2009 . The results showed that as the critical driving factor of soil erosion by water, the annual precipitation presented a small decreasing trend, but the spatial distribution of the precipitation changed significantly and the inconsistent trends in different time series existed apparently on the Loess Plateau.

\section{ACKNOWLEDGEMENTS}

The work was supported by the National Basic Research Program of China (973Program) (2007CB407203) and the National Natural Science Foundation of China (Grant No. 41101265). Thanks are also given Dr. David Jupp for the helpful comments.

\section{REFERENCES}

Easterling, D. R., Wallis, T. W. R., Lawrimore, J. H., Heim Jr, R. R. 2007. Effects of temperature and precipitation trends on US drought. Geophysical Research Letters, 34(20):L20709.

Førland EJ, Hanssen-Bauer I. 2000: Increased precipitation in the Norwegian Arctic: true or false? Clim Change 46(4):485-509.

Hansel, S., Petzold, S. and Matschullat, J.. 2009. Precipitation Trend Analysis for Central Eastern Germany 1851-2006. Bioclimatology and Natural Hazards 14:29-38.

Haylock, M., Peterson, T., Alves, L., Marengo, J., Ambrizzi, T., Anuncia o, Y., Rebello, E., Baez, J., Barros, V., Rusticucci, M. 2006. Trends in total and extreme South American rainfall in 1960-2000 and links with sea surface temperature. Journal of Climate, 19(8):1490-1512.

Held, I. M., Soden, B. J. 2006. Robust responses of the hydrological cycle to global warming. Journal of Climate, 19(21):5686-5699.

Intergovernmental Panel on Climate Change (IPCC) (2007), Climate Change 2007: The Physical Science Basis. Contribution of Working Group I to the Fourth Assessment Report of the Intergovernmental Panel on Climate Change, edited by S. Solomon, et al., Cambridge Univ. Press, Cambridge, U. K.

Jiang T, Kundzewicz ZW, Su BD. 2008. Changes in monthly precipitation and flood hazard in the Yangtze River Basin, China. International Journal of Climatology 28(11): 1471-1481.

Kendall, M. G. 1975. Rank Correlation Methods. Griffin, London, UK.

Mann, H. B. 1945. Nonparametric tests against trend. Econometrica: Journal of the Econometric Society, 13: 245-259.

Marengo J., Tomasella, J., UVO, C. 1998. Long-term stream flow and rainfall fluctuations in tropical South America: Amazônia, Eastern Brazil and Northwest Peru. J. Geophys. Res.103,1775-1783,

New, M., Todd, M., Hulme, M., Jones, P. 2001. Precipitation measurements and trends in the twentieth century. International Journal of Climatology, 21(15):1899-1922.

Sen PK. 1968. Estimates of the regression coefficient based on Kendall's tau. Journal of the American Statistical Association 39: 1379-1389.

Tang K.L. 1990. Regional soil erosion characteristics and its cortrolling approach on the Loess Plateau. Beijing: Chinese Science and Technology Press.

Xin, Z. 2009. Spatio-temporal Variation of Erosive Precipitation in Loess Plateau during Past 50 Years. Scientia Geographica Sinica, 29(6).

Xu ZX, J.Y.Li and C. M. Liu. 2007. Long-term trend analysis for major climate variables in the Yellow River basin. Hydrological Processes . 21:1935-1948 